\title{
Iodine levels in brands of salt on the markets of Accra, Ghana
}

\author{
George N. Doku and Emmanuel A. Bortey \\ Ghana Med J 2018; 52(3): 163-167 doi: http://dx.doi.org/10.4314/gmj.v52i3.10
}

Department of Pharmaceutical Sciences, Central University, P.O. Box 2305, Miotso, Tema, Ghana

Corresponding author: George N. Doku

E-mail: gndoku@hotmail.com

Conflict of interest: None declared

\begin{abstract}
SUMMARY
Introduction: The analysis sought to verify the presence or otherwise and the concentration levels of iodine in the claimed iodated salts on the Ghanaian market.

Methods: Eleven (11) most patronized brands of salts, including both local and foreign brands and the raw-pellet salt (crystallized directly from sea water), were obtained from popular shops and markets in Accra. These were analysed both qualitatively and quantitatively by titrimetry, involving the iodate-iodide reaction in acid medium that generates molecular iodine $\left(\mathrm{IO}_{3}^{-}+\mathrm{I}^{-}+6 \mathrm{H}^{+} \rightarrow \mathrm{I}_{2}+3 \mathrm{H}_{2} \mathrm{O}\right)$.

Results: The iodine content (in ppm) at retail, recorded for the samples are as follows: Sample A (25.4), B (51.8), C (52.9), D (45.5), E (25.4), F (75.1), G (28.6), H (0), I (13.7), J (34.9) and K (16.9). No iodine was observed in the raw-pellet salt (sample $\mathrm{H}$ ) crystallized directly from sea water, in contrast to the long-held belief that it contains natural iodine. Furthermore, all samples analyzed did not meet the concentration levels indicated on their labels and did not meet the Ghana Standard Authority's standard.

Conclusion: Only samples B and C were close to the Ghana Standard Authority's specification. The Ghana Standard Authority's standard of 100ppm at production and 50ppm at retail may be too high or, probably, the salt iodination companies are not adhering to the rules. The authors therefore recommend that the regulatory authorities (The Food and Drugs Authority and The Ghana Standard Authority) regularize their regulatory activities and educate the public appropriately.
\end{abstract}

Funding: The study was self-funded by the researchers/authors.

Keywords: Iodated salts; analysis; iodine levels.

\section{INTRODUCTION}

Various trace elements have been identified as being essential for optimal health, although this designation for some of them still awaits scientific consensus. These elements include chromium, cobalt, copper, fluoride, iodine, iron, manganese, molybdenum, selenium and zinc. Nutritionists are concerned about toxic levels (excess intake) and deficiencies of dietary contents and food supplements. ${ }^{1}$ The diet of more than a billion people in the world, mostly in the developing countries like Ghana, is deficient in iodine (a key micro nutrient). ${ }^{2}$ Iodine Deficiency Disorder (IDD) is a serious global public health problem. Iodine deficiency is considered the simple greatest cause of irreversible but preventable brain damage in the foetus, increased risk of abortions, still birth and mental retardation..$^{3-5}$ Excess intake is as devastating as its deficiency. Iodine-induced hyperthyroidism and thyrotoxicosis are possible outcomes. The desired daily consumption of iodine is at least $150 \mu \mathrm{g}$.
The iodine requirement for the prevention of Iodine Deficiency Disorder (IDD) in adults is between 75ug to $150 \mathrm{ug}$, which is approximately $1 \mathrm{ug} / \mathrm{kg}$ body weight. The need for iodine increases during puberty and pregnancy. ${ }^{1}$ Deficiency of iodine can be prevented or reduced by iodine supplementation of food. It is critical that the carrier for the nutrient be available for the entire population and must be consumed at constant rate irrespective of economic or social status. Among its carriers, common salt provides an attractive vehicle for iodine supplementation because of its uniform consumption and availability to all segments of the society and hence the introduction of iodated salt on our markets. Monitoring of the iodine content at the point of production of iodated salt and at the market place is necessary to ensure quality control. This would ensure strict adherence to the recommended levels of iodine in the salt. ${ }^{2,4}$ 
In view of this, the Ghana Standard Authority has set a limit in a statement which reads 'the iodine content in salt shall not be more than 100ppm at the factory level (production point) and expected to be 50ppm at the retail level. ${ }^{6}$ The World Health Organization (WHO), the United Nations International Children's Emergency Fund (UNICEF) and the International Centre for Control of Iodine Deficiency Disorders (ICCIDD) proposed that at the point of production, the iodine content in salt should be within the range of $20-40 \mathrm{mg}$ of iodine (i.e., 20-40 ppm) per kg of salt if the adult daily consumption of salt was $10 \mathrm{~g} /$ day. $^{7}$ This recommendation replaced that of $1993 .{ }^{8}$ Because $10 \mathrm{~g} /$ day is, however, excessive, the current recommendation of salt intake is $5 \mathrm{~g} /$ day. Despite positive achievements made in the last decade from implementation of universal salt iodination, such as reduction of iodine deficiency disorder (IDD) and decrease in goiter prevalence, iodine induced hyperthyroidism was documented in some countries and was clearly linked to iodine overload at the household level. ${ }^{7}$

Global effort to address iodine deficiency through salt iodization has resulted in dramatic improvement in the consumption of iodized salt from about $20 \%$ in the 1990 's to about $70 \%$ as at $2004 .{ }^{9}$ Nonetheless, the global goal of about $90 \%$ household using adequately iodized salt is yet to be realized. In Ghana a legislative instrument was passed in 1995 to drive a mandatory mass fortification of food grade salt with iodine. This intervention sought to ensure that at least $90 \%$ household consumed adequately iodized salt by 2001, however this was not achieved and the target of this national goal was reset to 2011. ${ }^{10}$ This piece of work was aimed at ascertaining the presence or otherwise (qualitative test) and to determine the levels of iodine (assay) in the various iodated salts on the Ghanaian market and compare with the iodine levels with recommended standards, and also to establish or otherwise, the long-held belief that raw salt from the Ada-Songo and Keta lagoon contain natural iodine.

Iodine belongs to the group VII elements, commonly referred to as halogens, on the periodic table. Its relatively high atomic number, low toxicity and high reactivity have made it part of many X-ray materials in modern medicines. Naturally, iodine occurs as the iodide $\left(\mathrm{I}^{-}\right)$ion in natural brines and as an impurity in Chile Saltpeter $\left(\mathrm{NaNO}_{3}\right)$. Like other halogens, it exists as a diatomic molecule $\left(\mathrm{I}_{2}\right)$ with weak Van der Waals forces (London dispersion forces) as inter molecular force of attraction. It is almost insoluble in water, but addition of potassium iodide increases its solubility through the formation of triiodide. Iodine undergoes both oxidation and reduction reactions, the most common reaction being the interconversion of $\mathrm{I}^{-}$and $\mathrm{I}_{2}\left(2 \mathrm{I}^{-} \leftrightharpoons \mathrm{I}_{2}\right) .{ }^{\mathbf{1 1}}$
Iodine reacts with the amylose portion of starch to give a blue-black coloration. This reaction was the basis for the qualitative aspect of this investigation. ${ }^{12}$

Several analytical methods are available for iodine detection and monitoring in salt. Among these are Inductively Coupled Plasma - Mass Spectrometry (ICP-MS), Radiochemical Neutron Activation Analysis, Titrimetric methods and Capillary Electrophoresis. All these methods meet the requirement of sensitivity and specificity. Titrimetry has, however, been the frequently used method in assay of iodine in the production of iodized salt because of its simplicity (relatively easy to use), accuracy (sensitivity and specificity), low cost and reliability. ${ }^{13}$ World bodies such as WHO, UNICEF and ICCIDD also recommend titrimetry as the method of choice for iodine assay in salt. These considerations formed the basis for the choice of titrimetry in this investigation. During salt iodination, two chemical forms of iodine, potassium iodate $\left(\mathrm{KIO}_{3}\right)$ and potassium iodide (KI), are commonly used. This is because the free iodine is almost insoluble in water and highly volatile even at ordinary temperatures as elemental iodine readily sublimes. ${ }^{2,4}$ Thus, the reactions employed in the titrimetric determination are as follows: the iodate-iodide reaction in acid medium that generates molecular iodine $\left(\mathrm{IO}_{3}{ }^{-}+5 \mathrm{I}^{-}+\mathbf{6 \mathrm { H } ^ { + }} \rightarrow \mathbf{3 \mathrm { I } _ { 2 }}+\mathbf{3} \mathrm{H}_{2} \mathrm{O}\right)$, followed by thiosulphate-iodine oxidation-reduction reaction $\left(2 \mathrm{Na}_{2} \mathrm{~S}_{2} \mathrm{O}_{3}+\right.$ $\left.\mathrm{I}_{2} \rightarrow 2 \mathrm{NaI}+\mathrm{Na}_{2} \mathrm{~S}_{4} \mathrm{O}_{6}\right)$.

\section{METHODS}

\section{Study area and sampling}

A verbal interview was conducted among marketers and consumers to verify the most patronized salt brands in Accra, the Ghanaian capital. Eleven (11) of these most patronized brands of claimed iodated salts, including both local and foreign brands and the raw-pellet salt (crystallized directly from sea water), were purchased from the markets at Kaneshie, Makola, Agblogbloshie and from the Shoprite shopping mall in Accra. The samples were labeled A to $\mathrm{K}$, the imported samples being $B, C$ and $D$, the raw-pellet salt being sample $H$, and the rest being the local iodated salts.

\section{Chemical analysis}

All apparatus and reagents $\left(\mathrm{H}_{2} \mathrm{SO}_{4}, \mathrm{KI}\right.$, starch) used in this project were provided by the Ghana Standard Authority and the experiment was conducted in the laboratory of the Ghana Standard Authority.

To verify the presence of iodine in these claimed iodated salts, $10 \mathrm{ml}$ of a $20 \% \mathrm{w} / \mathrm{v}$ solution of each salt sample were prepared and each transferred into a separate test tube, labeled accordingly and stoppered. 
To these test tubes, $1 \mathrm{ml}$ of $1 \mathrm{M} \mathrm{H}_{2} \mathrm{SO}_{4}$ solution and $5 \mathrm{ml}$ of a $10 \% \mathrm{KI}$ solution was added. The solution was expected to turn yellow and change to blue black (dark purple) coloration upon addition of freshly prepared starch indicator, if iodine was present. The assay (quantitative analysis) was done titrimetrically using iodometry as recommended by WHO/UNICEF/ICCIDD.

Ten grams (10g) of salt sample A was weighed in a $250 \mathrm{ml}$ conical flask and stoppered. Thirty millilitres (30ml) deionized water was added and swirled to dissolve. More deionized water was added to make up $50 \mathrm{ml}$. One millilitre $(1 \mathrm{ml})$ of $1 \mathrm{MH}_{2} \mathrm{SO}_{4}$ and $5 \mathrm{ml}$ of $10 \%$ KI solution were added. The flask was stoppered and placed in a dark cupboard for 10 minutes. The burette was filled with a standard $0.005 \mathrm{M} \mathrm{Na}_{2} \mathrm{~S}_{2} \mathrm{O}_{3}$ and titrated with the flask content until the solution turns pale yellow. $2 \mathrm{ml}$ starch indicator solution was added to the conical flask and titration continued until the solution had become colorless. The burette readings were recorded. This was repeated for all samples worked on and their respective burette recordings noted. All necessary precautions involved in iodine titration were observed. The iodine content in the various samples was then calculated.

\section{Calculations}

The method of calculation of iodine content was that contained in the operational chart/manual of the Ghana standards Authority. ${ }^{14}$

\section{Ethics}

Permission was sought from the Ghana Standard Authority who provided all apparatus and reagents and allowed the experiment to be conducted in their laboratory. In the view of the authors and of the Institutional Review Board of the Central University, since the research was a market surveillance, and did not involve any human or animal subjects or samples, there was no need for any formal ethical clearance letter on the study.

\section{RESULTS}

The results of qualitative test (to verify the presence of iodine in the claimed iodated salts), and the amounts of iodine in parts per million (ppm) present in the samples, calculated from the volumes of standard thiosulphate consumed (burette reading) are given in Table 1.

\section{DISCUSSION}

The qualitative analysis depended on the reaction, $\mathbf{I O}_{3}{ }^{-}$ $+\mathbf{5} \mathbf{I}^{-}+\mathbf{6} \mathbf{H}^{+} \rightarrow \mathbf{3 \mathbf { I } _ { 2 }}+\mathbf{3} \mathbf{H}_{2} \mathbf{O}$. All the samples worked on were labeled by the manufacturers as containing iodate $\left(\mathrm{KIO}_{3}\right)$ as the source of iodine, except for sample $\mathrm{H}$ (the raw-pellet salt) which was claimed by dealers to be containing natural iodine. Free iodine is expected to be lib- erated from the iodate on addition of acid and kept in a dissolved state by the presence of potassium iodide. The liberated free iodine goes into reaction with the amylose component of starch to give the characteristic dark purple (blue black) coloration.

Table 1 Results of iodine analysis of iodated salts

\begin{tabular}{|l|l|l|l|l|}
\hline Sample & $\begin{array}{l}\text { Result of } \\
\text { qualitative } \\
\text { text }\end{array}$ & $\begin{array}{l}\text { Iodine } \\
\text { content in } \\
\text { ppm at } \\
\text { retail }\end{array}$ & $\begin{array}{l}\text { \%Loss at } \\
\text { production } \\
\text { assuming } \\
\text { GSA } \\
\text { standard } \\
\text { of 100 } \\
\text { ppm }\end{array}$ & $\begin{array}{l}\text { Deviation } \\
\text { in iodine } \\
\text { content } \\
\text { at retail } \\
\text { from gsa } \\
\text { standard } \\
\text { of 50 } \\
\text { ppm }\end{array}$ \\
\hline A & + & 25.4 & 74.6 & -24.6 \\
B & + & 51.8 & 48.2 & +1.8 \\
C & + & 52.9 & 47.1 & +2.9 \\
E & + & 45.5 & 54.5 & -4.5 \\
F & + & 25.4 & 74.6 & -24.6 \\
G & + & 75.1 & 24.9 & +25.1 \\
H & - & 28.6 & 71.4 & -21.4 \\
I & + & 0 & 0 & -50 \\
J & + & 13.7 & 86.3 & -36.3 \\
\hline & $+\infty$ & 65.1 & -15.1 \\
\hline
\end{tabular}

From the analysis carried out positive qualitative results (blue colour) were observed with all industrially iodated samples (which means they contain iodine), while sample $\mathrm{H}$ (the raw-pellet salt) did not show any iodine present. The raw-pellet salt (or sea salt, also called bay or solar salt) is produced from the evaporation of sea water which contains some small amount of iodine as iodide ion. It is likely that this form of iodine is lost during the evaporation process since iodide ion easily interconverts into molecular iodine (2I- $\leftrightharpoons \mathrm{I}_{2}$ ) which is highly volatile and sublimates under ordinary temperatures. This may account for the absence of iodine in the raw-pellet salt.

The assay procedure was limited to only the samples that showed positive qualitative test; this was to estimate the actual iodine content in them. The amount of free iodine generated depended on the level of $\mathrm{KIO}_{3}$ present.

The generated iodine was then titrated against standard sodium thiosulphate solution according to the reaction, 
$\mathbf{2 N a}_{2} \mathbf{S}_{2} \mathbf{O}_{3}+\mathbf{I}_{2} \rightarrow \mathbf{2} \mathrm{NaNa}_{2} \mathbf{S}_{4} \mathbf{O}_{6}$. The endpoint was reached when all the free iodine $\left(\mathrm{I}_{2}\right)$ had been consumed by the standard thiosulphate as indicated by the disappearance of the purple coloration (a change to colorless) upon addition of the starch indicator.

The iodated salt samples B, C and D having good packaging and storage conditions showed results of iodine content close to their label claims of 50ppm. These brands could also have been produced from good manufacturing practices. In contrast, the iodized salts with worn-out packages and sometimes stored under direct sunlight, recorded wider deviations from their label claims, and in most cases (the only exception being sample F) very low levels were recorded.

It could be that these (samples A, E, G, I, J, K) salt iodination companies are not adhering to standard production rules and therefore could not meet the Ghana Standard Authority's requirement of $100 \mathrm{ppm}$ at production and 50ppm at retail (a 50\% loss from production to retail). If these samples A, E, G, I, J and K met the Ghana Standard Authority's requirement of $100 \mathrm{ppm}$ at production, then the very low levels recorded (lower than the expected label claim of 50ppm at retail) would imply that a higher than $50 \%$ loss had occurred (refer to Table 1) between production and retail, which could be due to the poor packaging and storage conditions. Sample $\mathrm{F}$, however, gave an iodine content of $75 \mathrm{ppm}$ (50\% higher than the label claim of 50ppm and representing a $25 \%$ loss from production). This could be due to the somewhat thicker plastic packaging material used; this offers a better protection against loses through evaporation than the packaging materials used by the other local manufacturers.

The WHO estimates a $20 \%$ loss from production level to household and a further $20 \%$ loss during cooking. ${ }^{7}$ WHO also predicts that, in order to meet an average daily requirement of $150 \mu \mathrm{g}$ iodine from an average salt intake of $10 \mathrm{~g}$ of salt a day, iodine concentration in salt at the point of production should be within the range of 20ppm to 40ppm. The research findings show that the Ghana standard of $100 \mathrm{ppm}$ at production and 50ppm at retail is rather too high. The expected 50 percent loss could still leave behind excess iodine for intake by consumers. Indeed, from the iodine concentrations determined for the samples, a $10 \mathrm{~g}$ average salt intake of all the samples, except for samples I and K, would provide more than the daily iodine requirement of $150 \mu \mathrm{g}$ if used directly without cooking, even though in most cases lower iodine levels than the label claims were observed.

With the current recommended 5g/day salt intake, only samples B, C, D and F would provide more than the daily iodine requirement. The higher Ghana standard was probably decided because most people in Ghana overcook their food. Countries like South Africa from where three of the imported samples came have their standard set within the range of 60ppm to $40 \mathrm{ppm}$ at the point of production. ${ }^{15}$ Croatia, which is recognized internationally as an iodine sufficient country, sets an obligatory salt iodization level of 25 ppm. ${ }^{16}$ The goal of iodine supplementation in salt is to provide the daily iodine requirement in the synthesis of very important hormones Thyroxine $\left(\mathrm{T}_{4}\right)$ and Triiodotyronine. ${ }^{17}$ This goal could be defeated if excess of iodine is administered as it has an antagonistic effect on the production of thyroid hormones. The result is Wolff-Chaikoff Effect which is the reduction in thyroid hormones caused by large amount of iodine ingestion. ${ }^{18}$ It is clear from this that there is only a thin line between therapeutic iodine concentration and toxic levels and therefore any guidelines to establish iodine standards should be without ambiguity.

The current stipulation of $50 \%$ loss from production to household does not quite meet this measure. The quality control measures required to achieve concentration and packaging standards appear not to be available to the iodated salt industry as many do not recruit the needed professionals. The presence of an impurity in salt plays a role in iodine loss. Our current standard is silent on the level of purity required of salt to be iodized. The decision on the level of purity for salt iodization should not be left in the hands of producers as the possibility to cut down cost is always high for every business.

One striking observation made was that, in the iodated salt industry Good Manufacturing Practices (GMP) is not a key requirement as opposed to the pharmaceutical industry. Products both imported and local, except for one, did not bear batch numbers and manufacturing dates.

\section{CONCLUSION AND RECOMMENDATIONS}

The raw-pellet salt crystallized directly from sea water by evaporation was found not to contain any iodine, discounting the long-held belief that it contains natural iodine; it does not provide any source of iodine. Ninety percent (90\%) of the packaged iodated salts on the Accra markets verified, irrespective of origin, did not conform to their label claims of iodine concentration.

Samples with better protective packages against losses deviated only slightly from their label claims of iodine content, whereas the other counterparts deviated widely from their label claims.

All but two (I and K) of the samples contain iodine contents that would provide iodine intakes in excess of the 
daily adult need of $150 \mu$ g. The Ghana approved iodine content standard of 100ppm at production and 50ppm at retail appears to be too high in comparison with the WHO projection.

The authors recommend that the regulatory authorities (The Food and Drugs Authority and The Ghana Standard Authority) regularize their regulatory activities and educate the public appropriately. These may include the following: (i) quality audit of all salt iodinization companies to verify their compliance with Standard Operating Procedures (SOP) and Good Manufacturing Practices; (ii) intensifying the occasional swoops of salts on the market and undertaking a survey to confirm or deny adherence to prescribed standards; and (iii) a standard purity level of salt should be set and added to the standards required of iodated salt.

\section{ACKNOWLEDGEMENT}

We are grateful to the Ghana Standard Authority who provided all apparatus and reagents and allowed the experiment to be conducted in their laboratory.

\section{REFERENCES}

1. Sue, R.W. Nutrition and Diet Therapy, $7^{\text {th }}$ edition, Mosby-Year Book Inc., 1993; pp 250-267.

2. Dunn, T.J. and Haar, D.V.F. Practical Guide to Correct Iodine Deficiency, WHO, 1990: pp 12-25.

3. Zimmerman, M.B, Joster, P.L. and Pandav, C.S.. Iodine Deficiency Disorders, Lancet; 2008; 372, 1251-1262.

4. Hetzel, B.S. Global progress in addressing Iodine Disorders through USI; The making of a Global Public Health Story, The first decade (1985-1998), SCN News; 2007;.35; 5-11. 5. Pandav, C.S; Arora, N.K; Krishna, A.; Sankar, R. and Karmarkar, M.G. Bulletin of WHO; 2000; 78; 975- 980.

6. Ghana Standards Ref no GS 154, 2001; pp 3-5.

7. Joint WHO/UNICEFF/ICCIDD-WHO/AFRO/NUT consultation Recommended iodine levels in salt and the guidelines for monitoring their adequacy and effectiveness; Geneva, 1996; 8-9 July, Document No. 97.2.

8. WHO/UNICEF/ICCIDD Assessment of Iodine Deficiency Disorder and Monitoring their elimination, a guide for Programme Managers, $2^{\text {nd }}$ edition, Geneva; 2002;.pp 6-10.

9. Dalmiya, N.; Damton-Hill; De Benoist, B., Andersson, $\mathrm{M}$. The role of UNICEF and WHO in eliminating Iodine Deficiency Disorders, Oxford University Press New Delhi; 2004; pp 52-72.

10. www.Ghanaweb.com/Ghana Homepage/NewsArchive/article ph ZID $=169179$. Nov $25^{\text {th }} 2013,7: 30 \mathrm{pm}$.

11. Wilberg, E.; Wilberg, N.; Holleman, A.F. Inorganic Chemistry, Academic press. 2001; pp 419-420.

12. Melentyva, G.; Antonova, L. Pharmaceutical Chemistry, Oxford Press. 1998; pp 173, 302, 382 and 416.

13. Marjan, K.; Fereidoun, A. and Mehdi, H. A review on Iodine determination methods in Salt and biological Samples, International Journal of Medical Sciences, 2013;.1(1), 140.

14. 'Determination of Iodine Content in Salt', Work Instruction Manual, UNICEF.

15. Joste, P.L; Weight, M.J.; Lombard, C.I. Assessment of iodine concentration in table salt at the production stage in South Africa; Bulletin of WHO. 2003;.81(7); pp 517-521.

16. Kusic, Z.; Jukic, J.; Rogan, S.A.; Juresa, V.; Dabelic, N.; Stankic, J. et al. Current status of Iodine intake in Croatia, CollAntropol; 2012;.36(1):123-128.

17. Rang, H.P.; Dale, M.M.; Ritter, J.M.; Flower, R.J. Pharmacology, $6^{\mathrm{TH}}$ Edition, Churchil Livingstone. 2007; pp 437.

18. Wolff, J. and Chaikoff, I.L. Plasma Inorganic Iodide as a Homeostatic Regulator of Thyroid Function, Journal of Biological Chemistry. 1998; 174 (2); 555-564. 